\title{
Mutations of the androgen receptor gene identified in perineal hypospadias
}

\author{
J A Batch, B A J Evans, I A Hughes, M N Patterson
}

\begin{abstract}
Hypospadias is a common urological abnormality and may occur in simple (glandular or penile) or severe forms (perineal). Perineal hypospadias often occurs in association with other genital abnormalities, such as bilateral cryptorchidism and micropenis, and may be the result of partial androgen insensitivity. We have investigated the androgen binding status and androgen receptor gene of boys from two unrelated families. The first pair of brothers had partial androgen insensitivity with perineal hypospadias, bilateral cryptorchidism, and micropenis, while the other boys had isolated perineal hypospadias. Qualitative androgen binding defects were shown in both sets of brothers and different point mutations of the androgen receptor gene were found in the two families. These findings suggest that the genital abnormalities in the affected brothers result from defects in the androgen receptor. Furthermore, severe familial hypospadias may be a previously unrecognised part of the phenotypic spectrum of the partial androgen insensitivity syndrome. This study provides valuable information for the genetic counselling of families affected by this $X$ linked genital abnormality.

(f Med Genet 1993;30:198-201)
\end{abstract}

Hypospadias is a disorder of male external genital development in which the urethral orifice is found on the ventral surface of the penis rather than at the tip of the glans. It is a relatively common congenital abnormality with an incidence of 0.2 to $0.6 \%{ }^{1}$ It may be classified as simple (glandular or penile) or severe (perineal) on the basis of the anatomical location of the urethral meatus. In three quarters of cases the hypospadias is glandular or penile in location and occurs in isolation. ${ }^{2}$ Perineal hypospadias is less common and usually occurs in association with severe genital abnormalities such as micropenis, bifid scrotum, and cryptorchidism. The aetiology of hypospadias is poorly understood although varying modes of inheritance have been deduced from family studies, and significant associations with environmental factors have also been noted. ${ }^{2}$

Male sexual differentiation is androgen dependent. It is therefore possible that hypospadias may result from abnormal androgen synthesis or action. Endocrine studies in hypospadias have, however, not yielded consistent results. We and others have shown normal gonadotrophin production with appropriate testosterone synthesis and metabolism in simple glandular or penile hypospadias. ${ }^{34}$ Conversely, perineal hypospadias has been reported to be caused by uncommon defects in testosterone biosynthesis, such as 17-ketosteroid reductase deficiency, $5 \alpha$-reductase deficiency, and $3 \beta$-hydroxysteroid dehydrogenase deficiency. ${ }^{5}$

The partial androgen insensitivity syndrome (PAIS) comprises a spectrum of disorders with a phenotype ranging from perineal hypospadias with cryptorchidism and micropenis (mild undervirilisation) to clitoromegaly and labial fusion (severe undervirilisation). ${ }^{6}$ Subjects with PAIS all have a normal 46,XY karyotype, normal testosterone synthesis and metabolism, but have a defect in target cell androgen action which may be the result of a defective androgen receptor. It has been estimated that 10 to $50 \%$ of boys with PAIS have androgen binding abnormalities, suggesting that they have an abnormality of the androgen receptor. ${ }^{78} \mathrm{~A}$ complete form (CAIS) also exists and is associated with female external genitalia and usually absent androgen binding. ${ }^{6}$

The androgen receptor (AR) gene is located on the $\mathrm{X}$ chromosome and comprises eight exons. ${ }^{910}$ Like other members of the steroid receptor superfamily, the androgen receptor protein is divided into three distinct functional domains: a C-terminal androgen binding domain encoded by exons $\mathrm{D}$ to $\mathrm{H}$, a central DNA binding domain (exons $\mathrm{B}$ and $\mathrm{C}$ ), and an $\mathrm{N}$ terminal domain (exon $\mathrm{A}$ ) which has a less well defined role in transcriptional regulation. ${ }^{112}$ Mutations have recently been identified in the androgen receptor gene in subjects with both complete and partial androgen insensitivity. ${ }^{613}$ As part of a larger study of patients with abnormal male sexual differentiation spanning a wide phenotypic range, ${ }^{14}$ we have studied four boys from two unrelated families to assess their androgen binding status and to determine whether androgen receptor gene abnormalities may be responsible for the genital abnormalities. Boys from the first family had perineal hypospadias, bilateral cryptorchidism, and micropenis and fulfilled the diagnostic criteria of the partial androgen insensitivity syndrome. In contrast, brothers from the second family had only isolated perineal hypospadias, a condition not usually considered to be part of the PAIS phenotypic spectrum.

\section{Patients}

FAMILY 1

The two brothers in this Kuwaiti family (subjects $1 \mathrm{~A}$ and 1B) were born to non-consanguineous parents and presented in the neonatal 
Results of androgen binding assay in the four boys. Normal values for the assay are given as mean (SD).

\begin{tabular}{lccc}
\hline Subject & $\left(\times 10^{-18} \mathrm{~B}_{\text {max }} / \mu \mathrm{gDNA}\right)$ & $\begin{array}{c}\mathrm{K}_{\mathrm{d}} \\
\left(\times 10^{-10} \mathrm{mmol} / \mathrm{l}\right)\end{array}$ & $\begin{array}{c}\text { Thermolability } \\
\left(\% \text { reduction at } 40^{\circ} \mathrm{C}\right)\end{array}$ \\
\hline 1A & 587 & $3 \cdot 5$ & 30 \\
$1 \mathrm{~B}$ & 628 & $4 \cdot 3$ & 31 \\
$2 \mathrm{~A}$ & 977 & $3 \cdot 1$ & 57 \\
2B & 2057 & $3 \cdot 1$ & 54 \\
Normal & $814(168)$ & $0 \cdot 91(0 \cdot 26)$ & $6(5)$ \\
\hline
\end{tabular}

period with very similar phenotypes consisting of severe perineal hypospadias, bilateral cryptorchidism, and micropenis. Neither boy had any other congenital abnormalities and male sex of rearing was assigned at birth. There was no family history of a similar disorder. Both brothers had a normal 46,XY karyotype. Results of endocrine investigations in the brothers showed normal testosterone biosynthesis and metabolism. As part of their investigation, genital skin fibroblasts grown from biopsies taken at the time of corrective hypospadias surgery were assayed for androgen binding (see Results). Intravenous pyelograms (IVP) and micturating cystourethrograms (MCUG) showed that neither brother had any upper renal tract abnormality. At puberty both boys had some spontaneous testicular enlargement, but little pubic hair development or penile enlargement. Neither boy responded to therapeutic trials of intramuscular testosterone given to augment pubertal virilisation. Both boys are now lost to follow up, so their functional status as adult males is unknown.

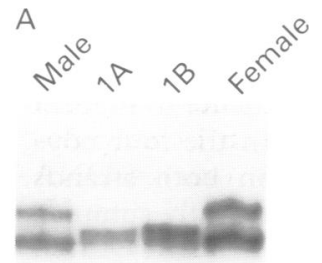

B
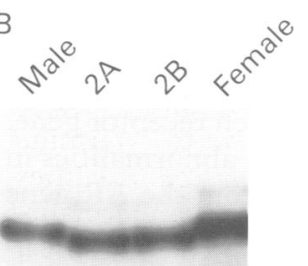

Figure 1 SSCP analysis of the androgen receptor gene. ( $A$ ) Band shift in amplified exon $G$ fragments from subjects $1 A$ and $1 B$. (B) Band shift in exon $H$ in subjects $2 A$ and $2 B$. The normal pattern for male and female controls is also shown for both exons. shown for both exons.
Both gels were run at $4^{\circ} \mathrm{C}$ without glycerol.

CUG to have a urethral diverticulum, with otherwise normal renal anatomy. Subject $2 B$ had no abnormalities of the upper renal tract. Both brothers have had corrective hypospadias surgery performed and are currently prepubertal.

\section{Methods}

TISSUE CULTURE

Fibroblast cell lines were established from genital skin biopsies obtained at surgery, by primary explantation in E199 medium containing $20 \%$ fetal calf serum and supplemented with penicillin, streptomycin, and glutamine as previously described..$^{15}$ The serum was reduced to $10 \%$ after the second passage and maintained at that level thereafter. Cells were grown at $37^{\circ} \mathrm{C}$ in $5 \% \mathrm{CO}_{2}$.
ANDROGEN BINDING ASSAY

Androgen binding was measured in genital skin fibroblasts using a whole cell binding assay. ${ }^{15}$ Parameters derived from this assay included the receptor concentration $\left(B_{\max }\right)$, binding affinity $\left(\mathrm{K}_{\mathrm{d}}\right)$, and the stability of androgen binding at $40^{\circ} \mathrm{C}$ (thermolability).

\section{PCR-SSCP ANALYSIS OF THE ANDROGEN} RECEPTOR GENE

The androgen receptor gene was screened for mutations using a rapid and sensitive technique, PCR-single strand conformation polymorphism (SSCP) described elsewhere. ${ }^{1416}$ Genomic DNA was prepared from genital skin fibroblasts by standard methods. ${ }^{17}$ Fourteen pairs of oligonucleotide primers were used to amplify the coding regions of the androgen receptor gene to yield segments less than 350 base pairs. ${ }^{14} \mathrm{~A} 10 \mu \mathrm{l}$ PCR reaction was used for SSCP as described. ${ }^{14}$ Stop buffer $(10 \mu \mathrm{l})$ containing $95 \%$ formamide, $20 \mathrm{mmol} / 1 \mathrm{EDTA}$, $0.05 \%$ bromophenol blue, and $0.05 \%$ xylene cyanol FF was added to the reactions. The samples were then denatured at $95^{\circ} \mathrm{C}$ for five minutes and stored on ice before loading on to non-denaturing polyacrylamide gels. A $40 \mathrm{~cm} \times 20 \mathrm{~cm}$ vertical gel apparatus incorporating fan cooling was used. Analysis was carried out using two sets of conditions for every PCR fragment since some mutations are not detected when only one set of running conditions is used. ${ }^{1416}$ Gels containing $6 \%$ acrylamide, $1 \times \mathrm{TBE}$ ( $90 \mathrm{mmol} / 1 \mathrm{Tris}$-borate, $\mathrm{pH} 8.2,2.5 \mathrm{mmol} / 1 \mathrm{EDTA})$ were run at $4^{\circ} \mathrm{C}$. Gels containing $10 \%$ glycerol, $6 \%$ acrylamide, $1 \times \mathrm{TBE}$ were run at room temperature. All gels were run at 12 watts in $1 \times$ TBE buffer. The bromophenol was run to the end of the gel and the gel was then dried before autoradiography. The polyglutamine region of exon A was not analysed by SSCP as it is highly polymorphic. ${ }^{1819}$ This region was analysed by direct sequencing. As well, PCR of the polyglycine region of exon $A$ has been shown to result in a truncated repeat length owing to the highly GC rich nature of the region. ${ }^{20}$ We have encountered similar problems with PCR of this region and have therefore not included analysis of the polyglycine stretch of exon $A$ in our study.

\section{DNA SEQUENCING OF PCR PRODUCTS}

Preparative PCR reactions were carried out in a total volume of $25 \mu \mathrm{l}$, as a scaled up version of the basic PCR reaction described. ${ }^{14}$ The PCR reaction was then loaded on to an agarose gel and the DNA extracted using the QIAEX ${ }^{\circledR}$ agarose gel extraction kit. A $50 \mu$ l asymmetrical PCR reaction ${ }^{21}$ was performed using $5 \mathrm{ng}$ DNA, a 20:1 ratio of primers (that is, 20 pmol: 1 pmol), $50 \mu \mathrm{mol} / 1 \mathrm{dNTPs}, 5 \mu \mathrm{l}$ Parr buffer (Cambio Ltd), and 1 unit of DNA Taq polymerase (Cambio Ltd). The PCR product tions and isopropanol precipitation. Subsequently the products were sequenced with the limiting primer using a Sequenase ${ }^{\circledR}$ kit. was purified by phenol and chloroform extrac- 


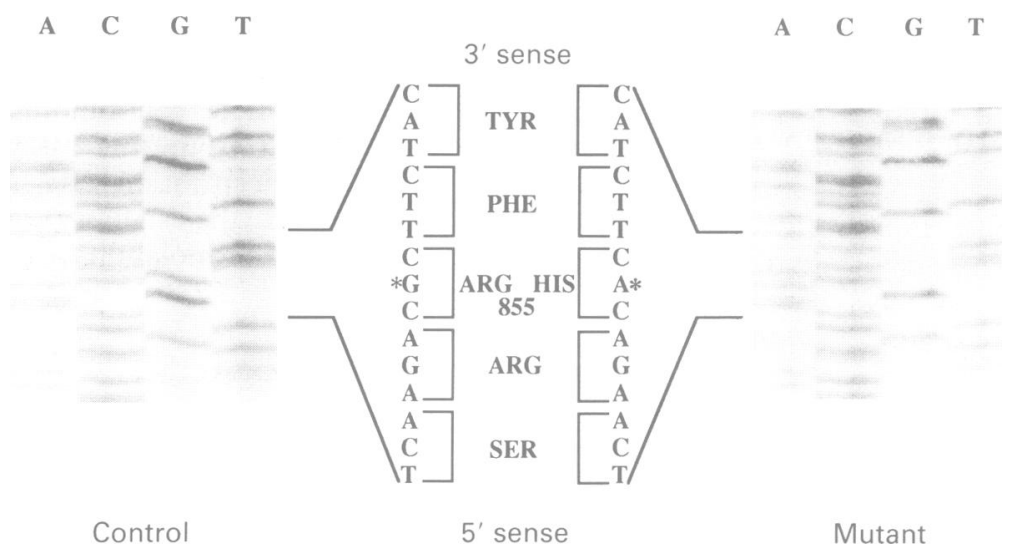

Figure 2 Sequencing of point mutations in exon $G$ in subjects $1 A$ and $1 B$. Portions of a sequencing gel are shown with a normal control on the left and the mutant on the right. The altered nucleotide is indicated by an asterisk, and the resultant amino acid change is also shown. The numbering used corresponds to Lubahn et al. ${ }^{22}$
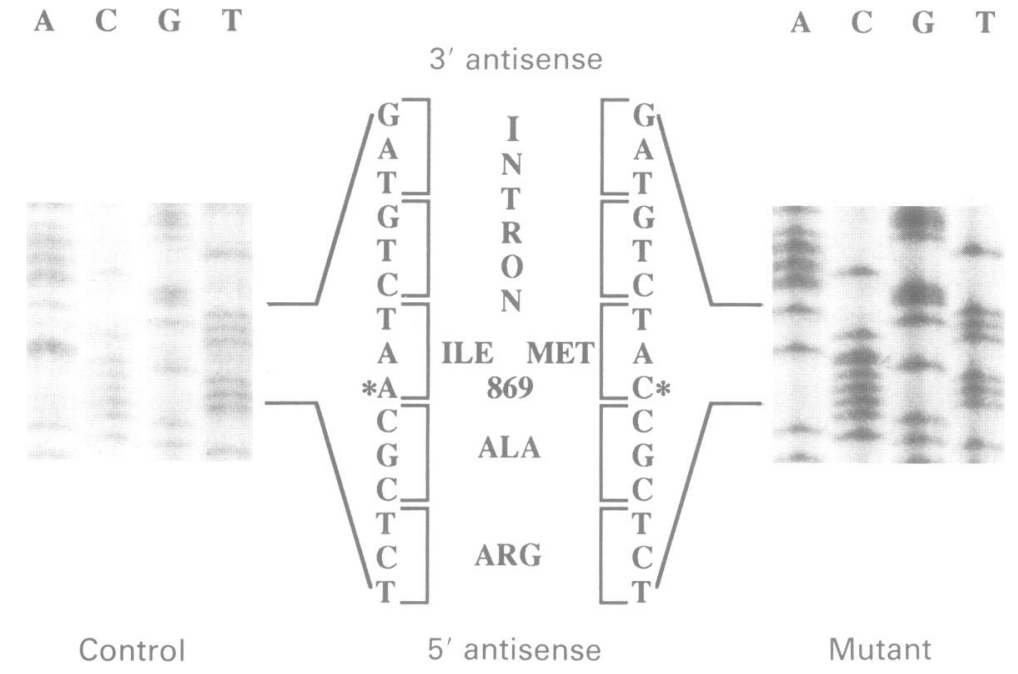

Figure 3 Sequencing of point mutations in exon $I I$ in subjects $2 A$ and $2 B$. The layout and labelling of this figure are the same as in fig 2.

\section{Results}

ANDROGEN BINDING ASSAY

The results of androgen binding assays for the four boys are shown in the table. Both pairs of brothers showed a clear qualitative defect in androgen binding indicated by the high $\mathrm{K}_{\mathrm{d}}$ (that is, low androgen binding affinity) and thermolability of binding. Receptor concentration was not diminished in any subject. The significance of the high $B_{\max }$ in subject $2 B$ is uncertain. These abnormal binding data suggested that the androgen receptor was defective.

\section{PCR-SSCP ANALYSIS}

The presence of mutations is indicated by a shift in the mobility of denatured PCR segments when run on a non-denaturing gel. In subjects $1 \mathrm{~A}$ and $1 \mathrm{~B}$, an abnormal DNA band shift compared to control DNA was found in exon G (fig 1A). This abnormality was detected readily under both sets of electrophoresis conditions outlined above. This was the only band shift detected in these boys. In subjects $2 \mathrm{~A}$ and $2 \mathrm{~B}$, an abnormal DNA band shift compared to control DNA was found in exon $\mathrm{H}$. Again the SSCP band shift was detected under both sets of conditions, but was more easily seen when the gel was run at $4^{\circ} \mathrm{C}$ without glycerol (fig 1B). No other abnormalities were detected in any other part of the gene examined. The band shift detected in subjects $2 \mathrm{~A}$ and $2 \mathrm{~B}$ was more subtle than that detected in subjects $1 \mathrm{~A}$ and $1 \mathrm{~B}$. SSCP analysis therefore suggested that subjects $1 \mathrm{~A}$ and $1 \mathrm{~B}$ carried an exon $G$ mutation, and subjects $2 A$ and $2 B$ an exon $\mathrm{H}$ mutation in the AR gene.

\section{DNA SEQUENCING OF PCR PRODUCTS}

The polyglutamine repeat region of exon $A$ consisted of 24 residues in subjects $1 \mathrm{~A}$ and $1 \mathrm{~B}$, and 27 residues in subjects $2 \mathrm{~A}$ and $2 \mathrm{~B}$ and was within the range defined for normal populations. ${ }^{18}$ No mutation was found in this region in the four boys. Direct sequencing of exon $G$ in subjects $1 \mathrm{~A}$ and $1 \mathrm{~B}$ confirmed the presence of a point mutation (guanine to adenine), causing an amino acid change from arginine to histidine at position 855 (fig 2). Sequencing of exon $\mathrm{H}$ in subjects $2 \mathrm{~A}$ and $2 \mathrm{~B}$ showed a point mutation (thymine to guanine), causing an amino acid change from isoleucine to methionine at position 869 (fig 3). In the four boys, mutations were sequenced on both strands. The mutations are diagrammatically summarised in fig 4 .

\section{Discussion}

This study shows that familial perineal hypospadias occurring alone or in association with cryptorchidism and micropenis may be associated with abnormal androgen binding and point mutations of the androgen receptor gene. The findings also suggest that abnormalities in androgen binding resulting from the AR gene mutations may be the cause of the abnormal genital development. Thus this study expands the phenotypic spectrum of PAIS to include

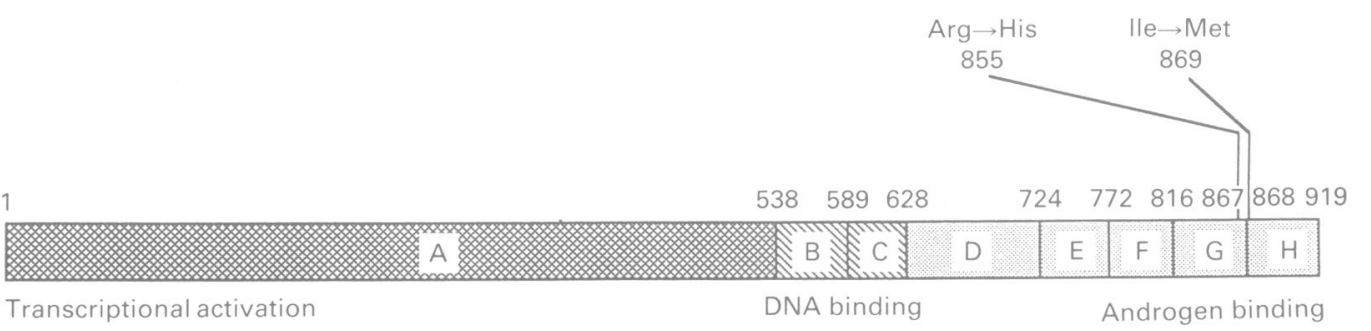

Figure 4 Androgen receptor gene mutations. The position of the mutations and the resulting amino acid changes are shown, in relation to the major functional domains of the AR. The boxes labelled $A$ to $H$ indicate the extents of the receptor encoded by each of the exons. ${ }^{22}$ 
familial perineal hypospadias. Inclusion of familial perineal hypospadias in the spectrum of PAIS allows appropriate genetic counselling of families affected by this $\mathrm{X}$ linked condition.

The mutations identified in the two families are within the androgen binding domain of the androgen receptor gene, consistent with the demonstrated qualitative androgen binding abnormalities. The same mutation at amino acid 855 (arginine to histidine) has previously been reported in a patient with PAIS $^{23}$ who had similar qualitative androgen binding abnormalities to our patients (subjects $1 \mathrm{~A}$ and 1B). In addition, an arginine to cysteine change at position 855 has also been identified in a CAIS patient with no detectable androgen binding. ${ }^{24}$ This less conservative amino acid change is consistent with the more severe binding defect and clinical phenotype. The mutation we have delineated at amino acid 869 in subjects $2 \mathrm{~A}$ and $2 \mathrm{~B}$ is unique. Other recent studies of PAIS have also shown AR gene mutations. ${ }^{1314}$ No study to date has documented AR gene mutations in isolated severe hypospadias, nor provided evidence that isolated severe hypospadias forms part of the partial androgen insensitivity syndrome. It is noteworthy that the subjects in our two families had virtually indistinguishable qualitative androgen binding abnormalities, yet showed a marked difference in the severity of the genital abnormality. A possible explanation is that the two AR gene mutations have different effects on target gene activation and full expression of androgenic effect. Expression studies of the mutant receptors could be designed to test this hypothesis and confirm that the mutations are responsible for the binding defect.

While these studies suggest that AR gene mutations are a cause of perineal hypospadias, it is unlikely that simple hypospadias is associated with AR gene abnormalities. However, in families in whom testosterone biosynthetic defects have been excluded as a cause of perineal hypospadias, we recommend that androgen binding studies be performed. If androgen binding abnormalities are found, then screening the AR gene may show a mutation responsible for the abnormal androgen binding and genital phenotype. The information gained may form the basis for appropriate genetic counselling in such families.

This work was supported by the Medical Research Council and the Wellcome Trust. JB was supported by grants from the Smith and Nephew Foundation, the University of Melbourne, Australia (The Henry and Rachael Ackman Travelling Scholarship in Medicine), the Royal Australasian College of Physicians (CRB Blackburn Scholarship), and the Royal Children's Hospital, Melbourne (Uncle Bob's Scholarship). Mr Scott and Mr Lari, paedia- tric surgeons, are gratefully acknowledged for obtaining samples at surgery for analysis.

1 Roberts C, Lloyd S. Observations on the epidemiology of simple hypospadias. BMF 1973;i:768-70.

2 Harris E. Genetic epidemiology of hypospadias. Epidemiol Rev 1990;12:29-40.

3 Evans B, Williams D, Hughes I. Normal postnatal androgen production and action in isolated micropenis and isolated hypospadias. Arch Dis Child 1991;66:1033-6.

4 Gearhart J, Linhard H, Berkovitz G, Jeffs R, Brown T Androgen receptor levels and 5a-reductase activities in preputial skin and chordee tissue of boys with isolated hypospadias. F Urol 1988;140:1243-6.

5 Savage M. Clinical aspects of intersex. In: Brook C, ed. Clinical paediatric endocrinology. 2nd ed. Oxford: Blackwell Scientific Publications, 1989:38-54.

6 Batch J, Patterson M, Hughes I. Androgen insensitivity syndrome. Reprod Med Rev 1992;1:131-50.

7 Schweikert $\mathrm{H}$. Schluter $\mathrm{M}$, Romalo G. Intracellular and nuclear binding of $\left[{ }^{3} \mathrm{H}\right]$-dihydrotestosterone in cultured genital skin fibroblasts of patients with severe hypospagenital skin fibroblasts of patients
dias. $\mathcal{F}$ Clin Invest $1989 ; 83: 662-8$.

8 Hughes I, Evans B. Androgen insensitivity in forty-nine patients: classification based on clinical and androgen receptor phenotypes. Horm Res 1987;28:25-9.

9 Lubahn D, Joseph D, Sullivan P, Willard H, French F Wilson E. Cloning of human androgen receptor complementary DNA and localization to the $\mathrm{X}$ chromosome. Science 1988;240:327-30.

10 Chang C, Kokontis J, Liao S. Molecular cloning of human and rat complementary DNA encoding androgen receptors. Science 1988;240:324-6.

11 Simental J, Sar M, Lane M, French F, Wilson E. Transcriptional activation and nuclear targeting signals of the criptional activation and nuclear targeting signals of the
human androgen receptor. $\mathcal{F}$ Biol Chem 1991;266:510-8.

12 Jenster $G$, van der Korput $H$, van Vroonhoven $C$, van der Kwast T, Trapman J, Brinkmann A. Domains of the human androgen receptor involved in steroid binding human androgen receptor involved in steroid binding,
transcriptional activation, and subcellular localization transcriptional activation, and sub

13 McPhaul M, Marcelli M, Tilley W, Griffin J, Wilson J. Androgen resistance caused by mutations in the androgen receptor gene. FASEB $\mathcal{f}$ 1991;5:2910-5.

14 Batch J, Williams D, Davies $\mathrm{H}$, et al. Androgen receptor gene mutations identified by SSCP in fourteen subjects with androgen insensitivity syndrome. Hum Mol Genet 1992;1:497-503.

15 Evans B, Jones T, Hughes I. Studies of the androgen receptor in dispersed fibroblasts: investigation of patients with androgen insensitivity. Clin Endocrinol 1984;20:93105

16 Orita M, Suzuki Y, Sekiya T, Hayashi K. Rapid and sensitive detection of point mutations and DNA polymorphisms using the polymerase chain reaction. Genomics 1989;5:874-9.

17 Sambrook J, Fritsch E, Maniatis T. Isolation of high molecular weight DNA from mammalian cells. In: Molecular cloning: a laboratory manual, Cold Spring Harbor NY: Cold Spring Harbor Laboratory Press, 1989:9.14 23.

18 Edwards A, Hammond H, Jin L, Caskey T, Chakraborty $R$. Genetic variation at five trimeric and tetrameric tandem repeat loci in four human population groups. Genomics 1992;12:241-53.

19 Sleddens H, Oostra B, Brinkmann A, Trapman J. Trinucleotide repeat polymorphism in the androgen receptor leotide repeat polymorphism in the andro
gene (AR). Nucleic Acids Res 1992;20:1427.

20 Marcelli M, Tilley W, Wilson C, Griffin J, Wilson J, Marcelli M, Tilley W, Wilson C, Griffin J, Wilson J,
McPhaul M. Definition of the human androgen receptor McPhaul M. Definition of the human androgen receptor
gene structure permits the identification of mutations that gene structure permits the identification of mutations that
cause androgen resistance: premature termination of the receptor protein at amino acid residue 588 causes complete androgen resistance. Mol Endocrinol 1990;4:110516.

21 McCabe P. Production of single-stranded DNA asymmetric PCR. In: Innis $M$, Gelfand $D$, Sninsky J, White $T$ eds. PCR protocols. San Diego: Academic Press, 1990:7683.

22 Lubahn D, Brown T, Simental J, et al. Sequence of the intron/exon junctions of the coding region of the human androgen receptor gene and identification of a poin mutation in a family with and identification of a poin mutation in a family with complete androgen
ity. Proc Natl Acad Sci USA 1989;86:9534-8.

23 Chang Y, Migeon C, Brown T. Human androgen insensitivity syndrome due to androgen receptor gene point mutations in subjects with normal androgen receptor mutations in subjects with normal androgen receptor
levels but impaired biological activity. 73rd Annual Meeting of The Endocrine Society, Washington DC, 1991:37 ing of The Endoc

24 de Bellis A, Quigley C, Cariello N, Ho K, French F. DNA and steroid binding domain mutations of the androgen receptor cause partial or complete androgen insensitivity. 73rd Annual Meeting of The Endocrine Society, Washington DC, 1991:316 (abstract 1141). 